\title{
Incidence and spectrum of chromosome abnormalities in spontaneous abortions: New insights from a 12-year study
}

${ }^{\star}$ Joshua Menasha, $M D^{1}$, ${ }^{\star}$ Brynn Levy, MSc (Med), PhD ${ }^{1-3}$, Kurt Hirschhorn, $M D^{1,2}$, and Nataline B. Kardon, $M D^{1-3}$

\begin{abstract}
Purpose: Despite advances in harvesting and culturing techniques, analysis of the impact of these improvements on the observed frequency of chromosomal abnormalities in spontaneous abortions (SAB) has not been determined. We sought to evaluate the effect of these refinements on the success rate of our cultures and on the resulting frequency of detected chromosomal abnormalities. Methods: Between 1990 and 2002, 2301 specimens obtained from the products of conception (POC) of SABs were submitted to our laboratory for cytogenetic analysis. Due to refinements in specimen processing and culture techniques introduced at the end of 1997, our data were analyzed for two periods: Period A from 1990 through 1997 with 907 eligible specimens and Period B from 1998 through 2002 with 1273 eligible specimens. Results: Modifications in physician communication and sample processing contributed to significant improvements in the culture success rate and in the ratio of male-to-female cases with normal karyotypes. Additionally, increased detection of trisomic, triploid, and multiple aneuploid cases in Period $B$ resulted in a significant increase in the percentage of cases with abnormal karyotypes $(42.8 \%$ in Period A vs. $65.8 \%$ in Period B). Monosomy $X$ accounted for $<10 \%$ of all abnormalities in Period B. Eighty five multiple aneuploid karyotypes, including 57 double trisomies, comprised $7.7 \%$ of our 1099 abnormal cases. These karyotypes were detected predominantly in POCs from the older women in our study. This collection of multiple aneuploidies is the largest published to date and includes abnormalities not reported in prior studies. We also present a table empirically derived from the data in Period B that indicates the likelihood of a specific abnormal karyotype based on maternal age. The table can be utilized by health care providers, who counsel patients after a spontaneous miscarriage. Conclusion: Improvements in laboratory technique have led to reduced contamination and growth failure of POCs, irrespective of maternal age. This in turn has led to a more balanced male-to-female ratio and to the detection of an increased number of abnormal cases. Genet Med 2005:7(4):251-263.
\end{abstract}

Key Words: cytogenetics, spontaneous abortion, aneuploidy, karyotype, chromosome abnormality

A correlation between chromosomal abnormalities and spontaneous abortions (SABs) has been observed since the 1960s. ${ }^{1}$ This correlation was strengthened in the 1970 s when Boue et al. ${ }^{2}$ published one of the earliest large cytogenetic studies. In the study, almost 1500 samples of fetal tissue were karyotyped and an abnormality rate of over $60 \%$ was found. Subsequent large studies using harvested products of conception (POC) failed to match this abnormality rate, with rates of $32 \%-54 \%$ reported. $^{3-9}$ Furthermore, a large number of specimens in these studies failed to grow successfully in culture and

\footnotetext{
From the ${ }^{1}$ Departments of Human Genetics, ${ }^{2}$ Pediatrics, ${ }^{3}$ Obstetrics, Gynecology, and Reproductive Sciences, Mount Sinai School of Medicine, New York, New York.

Dr. Brynn Levy, Departments of Human Genetics, Mount Sinai School of Medicine, Box 1497, One Gustave L. Levy Place, New York, NY 10029.

${ }^{*}$ Both authors contributed equally to this study.

Received: August 31, 2004.

Accepted: January 21, 2005.
}

DOI: 10.1097/01.GIM.0000160075.96707.04 thus could not be evaluated for abnormalities. The data culled from these studies have served as the basis for the estimated abnormality rates in the general population even to this day.

In the mid-1980s, a shift in cytogenetic techniques emerged, as studies utilizing chorionic villi from POCs began to appear in the literature. ${ }^{10-14}$ These studies had a much lower rate of culture failure and a higher abnormality rate. Unfortunately, most of these studies were of small sample size and some involved women of more advanced age. This improvement in methodology, coupled with advances in the detection of early pregnancy, supported the belief that the incidence of chromosome abnormalities was greater than previously estimated. ${ }^{15,16}$ Certain trends, however, have remained unchanged. Aneuploidy continues to account for the largest proportion of abnormalities observed in POCs. ${ }^{17}$ Although many theories have been proposed, the exact causes for this high rate of aneuploid conceptions in humans have remained unclear. ${ }^{18-20}$ Furthermore, multiple aneuploidies continue to be reported infrequently in the literature, predominantly as sporadic case reports, some involving liveborn conceptuses. ${ }^{21-23}$ 
Advances in technology and techniques continue to improve our diagnostic abilities. The utilization of comparative genomic hybridization (CGH) and interphase fluorescence in situ hybridization (iFISH) has allowed cytogenetic laboratories to evaluate POC samples that have failed to grow..$^{24,25}$ In order to determine the impact of these new techniques, an accurate representation of current abnormality rates, which reflect current reproductive trends, is needed to serve as a comparison.

In this report, we present a large collection of data spanning a 12-year period in an attempt to assess the impact these various methodological changes have had on the detection rate of abnormalities in POCs. With this study, we hope to provide an update and to add an additional perspective to the current knowledge of cytogenetic abnormalities in SABs.

\section{MATERIALS AND METHODS}

Between 1990 and 1997, spontaneously aborted samples from patients in our institution were usually forwarded to the cytogenetics laboratory after being processed in the Pathology Department. The samples were then set up using standard solid tissue techniques. Small pieces of tissue were minced manually and placed in a T-25 tissue culture flask with the addition of appropriate tissue culture media after the cells were attached. This method, along with similar techniques utilized in previous studies, is referred to throughout this article as POC harvesting.

In the latter part of 1997, a concerted effort was made to change the specimen handling and culturing processes. Referring obstetricians were contacted and instructed to send their specimens directly from the operating room or their offices to the cytogenetics laboratory. After culture initiation, the staff of the cytogenetics laboratory then forwarded the remaining portion of the specimen to the Pathology Department. In addition, the Pathology Department agreed to contact the cytogenetics laboratory before placing specimens in formalin, if they noted a request for cytogenetic studies.

In 1997, modifications were also made in the culturing process. A diligent effort was made to carefully dissect chorionic villi from placental tissue as well as tissue from fetal parts. An enzyme mixture consisting of collagenase, hyauronidase, and DNAase was used to digest the POC villi. The digested cells were centrifuged and plated on coverslips (in situ diagnostic CVS protocol) in addition to being set up in tissue culture flasks. This method, and similar methods reported in previous studies, is referred to in this article as CV harvesting. If no villi or fetal parts were recovered from the specimen, the attending obstetrician was notified and, in most cases, the request for cytogenetic analysis of the POC was cancelled.

The study protocol was submitted to and approved by the Institutional Review Board of the Mount Sinai School of Medicine. Data were collected retrospectively from records of all of the specimens processed by the cytogenetics laboratory from January 1990 through December 2002. Between January 1990 and April 1997, results and demographic data were recorded in logbooks. After April 1997, results were entered into a pass-

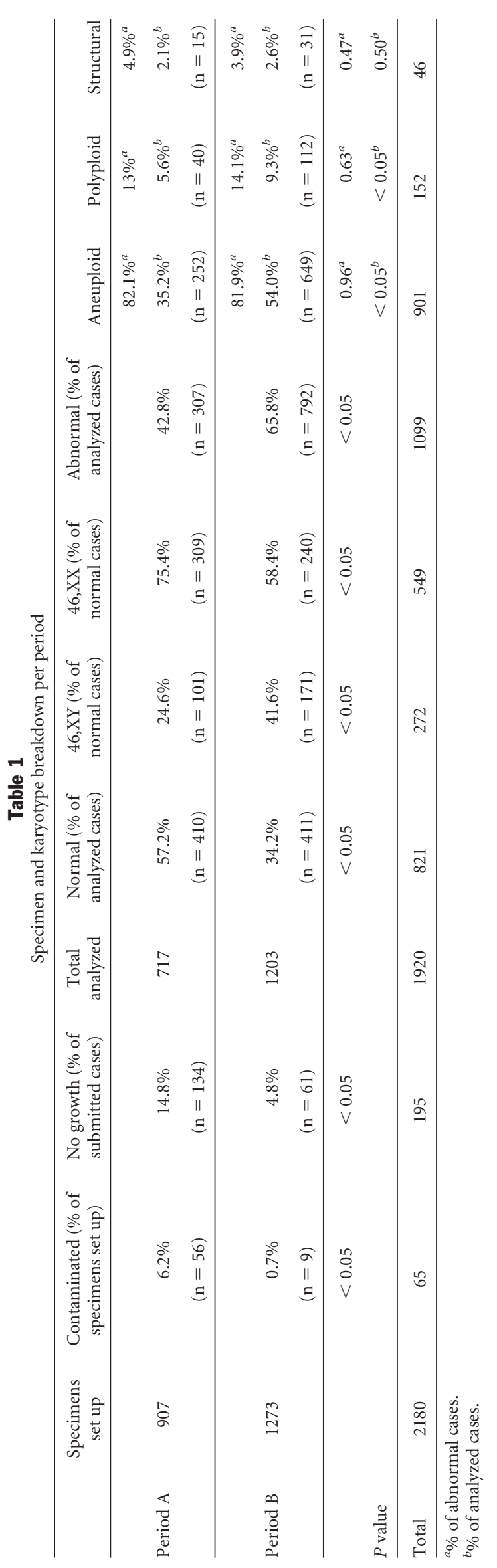


word-protected computerized database. Only those patients with documented spontaneous abortions were used in the study. POC specimens from induced abortions sent to the laboratory for confirmation of abnormal results obtained by CVS or amniocentesis were not included in the study.

Of the initial 2301 specimens eligible for study, 121 were excluded, thus bringing the total to 2180 . Reasons for exclusion included cancellation by the ordering physician, submission for research purposes, or inappropriate collection of the POC.

Results from each year were analyzed and divided into two specific blocks of time, with 1990 to 1997 forming Period A and 1998 to 2002 forming Period B. These dates were selected based on the modifications in laboratory procedure discussed earlier. Chi-square analyses were used to check for homogeneity of our results within each time period.

Because advanced maternal age is associated with an increased risk of fetal chromosome abnormalities, the ages of the women in the two groups were evaluated. Age data were available for only approximately one-third of the cases in Period A, due to the format of the logbooks used predominantly from 1992 through 1996. As will be discussed subsequently, independent sample $t$ tests assessed whether maternal age was different between the two groups and could thus affect our results. Chi-square analysis was performed to determine whether there were abnormal distributions of ages within each time period that could account for the average ages obtained. Finally, linear regression was applied and the data were reanalyzed using only those cases for which maternal age was available. With rare exception, this analysis failed to alter the significance of our results.

Chi-square analyses were used to determine whether there was an association between the laboratory findings and the time periods. In order to determine whether maternal age or the time required for sample analysis correlated with specific karyotype results, independent sample $t$ tests were used. An overall significance level of 0.05 was used in this study. SPSS and Microsoft Excel with Statplus software were used for the analysis of the data. All of the results were reviewed by a statistician from the Department of Biomathematics of the Mount Sinai School of Medicine.

\section{RESULTS}

\section{Comparison of Periods A and B}

Table 1 shows the number of contaminated and no growth cases, the sex ratio of the normal karyotypes, and the proportion of abnormal karyotypes for Periods A and B. The distribution of the various types of abnormalities within the abnormal category did not differ between the two periods, with aneuploidies, polyploidies, and structural abnormalities accounting for approximately $82 \%, 14 \%$, and $4 \%$ of the abnormalities, respectively.

\section{Aneuploidy}

Cases within the aneuploid group were divided into trisomy, monosomy, multisomy, and mosaic categories (Table 2).

\section{Trisomy}

The proportion of aneuploid cases and the proportion of abnormal cases that were trisomies did not significantly differ between the two periods. Trisomies, however, composed a significantly larger proportion of all of the cases analyzed in Period $\mathrm{B}$ compared to Period $\mathrm{A}$.

Figure 1 shows the chromosome distribution of the 723 cases with an extra chromosome. These numbers differ slightly from the trisomies reported in Table 2 due to the inclusion of mosaic and complex karyotypes that contained a trisomic cell line and the exclusion of the 5 cases with a marker chromosome. Although every chromosome was represented in this figure, the frequencies of the individual chromosomes varied greatly. Trisomy 16 was the most common (18.3\% of all trisomies and $12.0 \%$ of all 1099 abnormal cases), followed closely by trisomy 21 and trisomy 22 . Trisomy 1 and trisomy 19 were the least common, with only one case of each found (both in Period B) over the 12-year period. Figure 1 also shows the distribution of each trisomy within its respective time period (201 cases in Period A and 522 cases in Period B). In Period A, trisomy 21 was the most common trisomy $(23.9 \%$ of trisomies and $15.6 \%$ of all abnormalities within period A) followed by 16,22 , and 18 ; whereas in Period B, trisomy 16 was the most common (18.4\% of trisomies and $12.1 \%$ of all abnormalities within period B), followed by 22, 21, and 15 .

Table 2

Categories of aneuploid karyotypes

\begin{tabular}{|c|c|c|c|c|c|}
\hline & Trisomy & Monosomy & $\begin{array}{c}\text { Multiple } \\
\text { Aneuploidy }\end{array}$ & Mosaic & $\begin{array}{c}\text { Total } \\
\text { Aneuploid }\end{array}$ \\
\hline & $79 \%^{a}$ & $16.8 \%^{a}$ & $3.6 \%^{a}$ & & \\
\hline \multirow[t]{4}{*}{ Period A } & $64.8 \%^{b}$ & $13.7 \%^{b}$ & $2.9 \%^{b}$ & & $82.1 \%^{b}$ \\
\hline & $27.8 \%^{c}$ & $5.9 \%^{c}$ & $1.3 \%^{c}$ & & $35.2 \%^{c}$ \\
\hline & $(\mathrm{n}=199)$ & $(\mathrm{n}=42)$ & $(\mathrm{n}=9)$ & $(\mathrm{n}=2)$ & $(\mathrm{n}=252)$ \\
\hline & $80.4 \%^{a}$ & $10.3 \%^{a}$ & $9.0 \%^{a}$ & & \\
\hline \multirow[t]{4}{*}{ Period B } & $65.9 \%^{b}$ & $8.5 \%^{b}$ & $7.3 \%^{b}$ & & $81.9 \%^{b}$ \\
\hline & $43.4 \%^{c}$ & $5.6 \%^{c}$ & $4.8 \%^{c}$ & & $54.0 \%^{c}$ \\
\hline & $(\mathrm{n}=522)$ & $(\mathrm{n}=67)$ & $(\mathrm{n}=58)$ & $(\mathrm{n}=2)$ & $(\mathrm{n}=649)$ \\
\hline & $0.62^{a}$ & $<0.05^{a, d}$ & $<0.05^{a}$ & & \\
\hline \multirow[t]{2}{*}{$P$ value } & $0.73^{b}$ & $<0.05^{b, d}$ & $<0.05^{b}$ & & $0.96^{b}$ \\
\hline & $<0.05^{c}$ & $0.79^{c}$ & $<0.05^{c}$ & & $<0.05^{c}$ \\
\hline Total & $(\mathrm{n}=721)$ & $(\mathrm{n}=109)$ & $(\mathrm{n}=67)$ & $(\mathrm{n}=4)$ & $(\mathrm{n}=901)$ \\
\hline
\end{tabular}




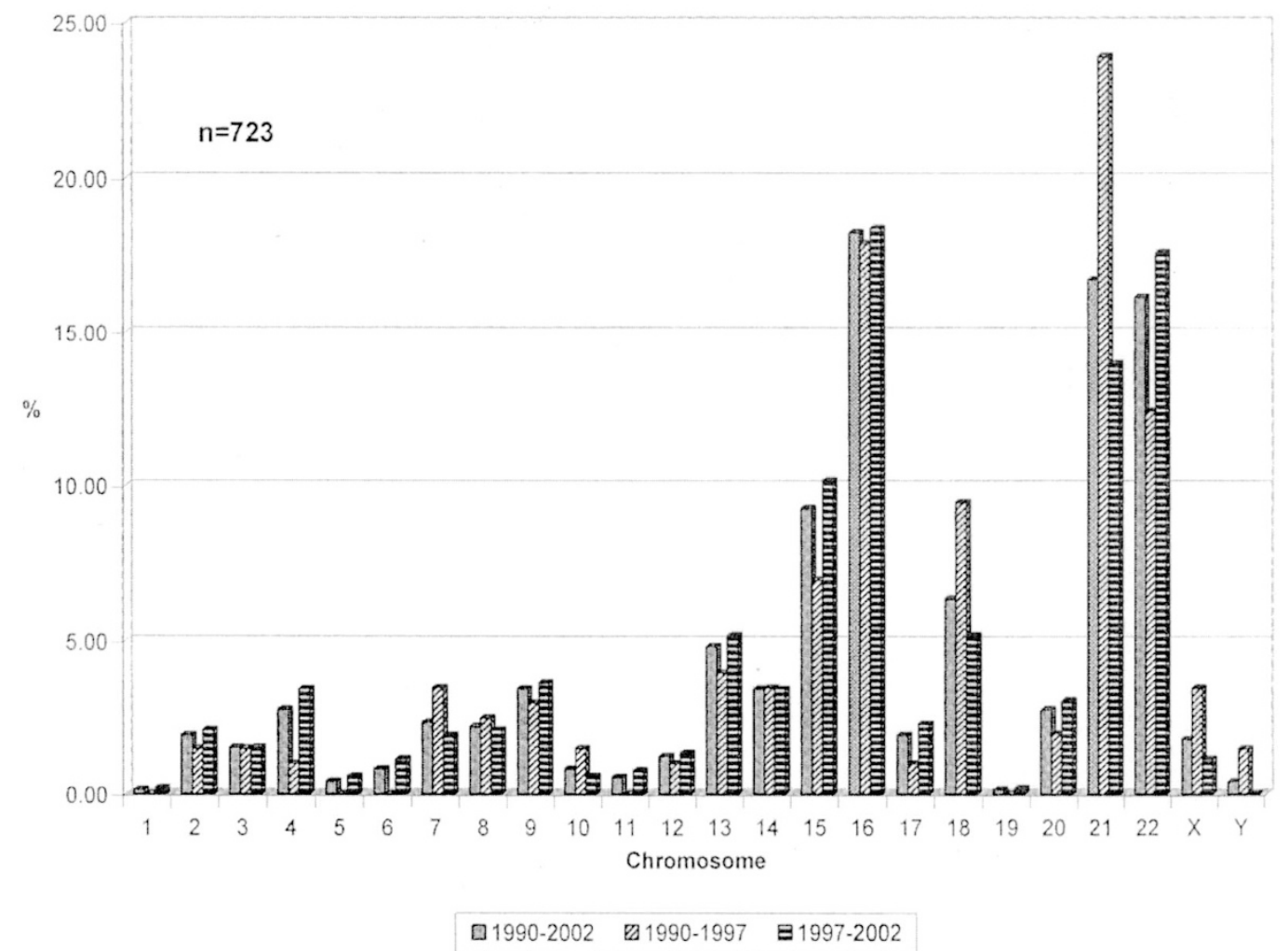

Fig. 1. Incidence of individual chromosomes among the trisomy cases.

\section{Monosomy}

In Period A, all 42 monosomies were 45,X. Monosomy X was found in $54(80.6 \%)$ of the 67 monosomies found in Period $\mathrm{B}$, and accounted for $6.8 \%$ of all abnormalities within this period. Monosomy 21 accounted for $85 \%$ of the autosomal monosomies and for $16.4 \%$ of all monosomies found in Period B. Monosomies accounted for a significantly lower proportion of the aneuploid and abnormal cases in Period B than in Period A. When linear regression was applied, however, this difference was no longer statistically significant.

\section{Multiple aneupolidy}

The multiple aneuploidy category consisted of POCs with aneuploidy of two or more chromosomes. Further details regarding this unique category are found in the multiple aneuploid section of this article. A full listing is found in Appendix A.

\section{Mosaic}

If a mosaic case contained a cell line with trisomy, that trisomy was also included in the data presented in Figure 1.

\section{Polyploidy}

The Polyploid group was divided into triploid, tetraploid, near/pseudo polyploid, and mosaic categories (Table 3).

\section{Triploid and Tetraploid}

The percentage of polyploid cases as well as the percentage of all abnormal cases that were triploid or tetraploid did not significantly differ between the two periods. Triploidy, however, did compose a significantly larger proportion of all of the analyzed cases in Period B.

\section{Near/Pseudo Polyploid}

This category consisted of either triploid or tetraploid specimens that had any number of additional or missing chromosomes. These results are discussed below along with the multisomy karyotypes.

\section{Mosaic}

The mosaic category contained those polyploid cases that had multiple cell lines, including some with aneuploidy. A listing of these cases is found in Appendix A.

\section{Multiple aneuploidy}

These 85 cases made up 4.4\% of the 1920 cases analyzed and $7.7 \%$ of the 1099 abnormal karyotypes. Multiple aneuploidies comprised a significantly greater proportion of the abnormal cases and of the total analyzed cases in Period B (Table 4; Appendix A).

All chromosomes were represented in the multiple aneuploid group except for 1 and 17. Figure 2 displays thefrequency 
Table 3

Categories of polyploid karyotypes

\begin{tabular}{|c|c|c|c|c|c|}
\hline & Triploid & Tetraploid & $\begin{array}{c}\text { Near/Pseudo } \\
\text { Polyploid }\end{array}$ & Mosaic & Total Polyploid \\
\hline & $80 \%^{a}$ & $12.5 \%^{a}$ & & & \\
\hline \multirow[t]{4}{*}{ Period A } & $10.4 \%^{b}$ & $1.6 \%^{b}$ & & & $13.0 \%^{b}$ \\
\hline & $4.5 \%^{c}$ & $0.7 \%^{c}$ & & & $5.6 \%^{c}$ \\
\hline & $(\mathrm{n}=32)$ & $(\mathrm{n}=5)$ & $(\mathrm{n}=2)$ & $(\mathrm{n}=1)$ & $(\mathrm{n}=40)$ \\
\hline & $75 \%^{a}$ & $11.6 \%^{a}$ & & & \\
\hline \multirow[t]{4}{*}{ Period B } & $10.6 \%^{b}$ & $1.6 \%^{b}$ & & & $14.1 \%^{b}$ \\
\hline & $7.0 \%^{c}$ & $1.1 \%^{c}$ & & & $9.3 \%^{c}$ \\
\hline & $(\mathrm{n}=84)$ & $(\mathrm{n}=13)$ & $(\mathrm{n}=12)$ & $(\mathrm{n}=3)$ & $(\mathrm{n}=112)$ \\
\hline & $0.52^{a}$ & $0.88^{a}$ & & & \\
\hline \multirow[t]{2}{*}{$P$ value } & $0.93^{b}$ & $0.99^{b}$ & & & $0.63^{b}$ \\
\hline & $<0.05^{c}$ & $0.40^{c}$ & & & $<0.05^{c}$ \\
\hline Total & $(\mathrm{n}=116)$ & $(\mathrm{n}=18)$ & $(\mathrm{n}=14)$ & $(\mathrm{n}=4)$ & $(\mathrm{n}=152)$ \\
\hline
\end{tabular}

${ }^{a} \%$ of polyploid cases.

${ }^{b_{\%}} \%$ of abnormal cases.

${ }^{c} \%$ of analyzed cases.

Table 4

Categories of multiple aneuploidy karyotypes

\begin{tabular}{|c|c|c|c|c|c|c|c|c|}
\hline & $\begin{array}{l}\text { Double } \\
\text { trisomy }\end{array}$ & $>49$ Chromosomes & Pseudodiploid & $\begin{array}{c}\text { Near } \\
\text { triploid }\end{array}$ & $\begin{array}{c}\text { Near } \\
\text { tetraploid }\end{array}$ & Mosaic & Complex & Total \\
\hline & & & & & & & & $3.6 \%^{a}$ \\
\hline \multirow[t]{3}{*}{ Period A } & 8 & 0 & 1 & 0 & 1 & 1 & 0 & $1.5 \%^{b}$ \\
\hline & & & & & & & & $(\mathrm{n}=11)$ \\
\hline & & & & & & & & $9.3 \%^{a}$ \\
\hline \multirow[t]{3}{*}{ Period B } & 46 & 6 & 6 & 7 & 5 & 2 & 2 & $6.2 \%^{b}$ \\
\hline & & & & & & & & $(\mathrm{n}=74)$ \\
\hline & & & & & & & & $<0.05^{a}$ \\
\hline$P$ value & & & & & & & & $<0.05^{b}$ \\
\hline Total & 54 & 6 & 7 & 7 & 6 & 3 & 2 & $(\mathrm{n}=85)$ \\
\hline
\end{tabular}

$a_{\%}$ of abnormal cases.

${ }^{b} \%$ of analyzed cases.

of a specific chromosome in the 85 cases. If a chromosome had more than one extra or missing copy (e.g., five copies of a chromosome in a triploid karyotype), the chromosome was only counted once. Chromosomes 21, 16, 22, and 15 were found most frequently in $28.2 \%, 21.2 \%, 18.8 \%$, and $18.8 \%$ of the 85 multiple aneuploidies, respectively. Sixteen (18.8\%) of the 85 cases had at least one missing chromosome.

Double trisomies were found in $54(63.5 \%)$ of the multiple aneuploid cases. An additional three cases had double trisomies as well as another abnormality (i.e., derivative chromosome or mosaicism), bringing the total to 57 cases (67.1\%). Further delineation can be found in Figure 3. Forty-eight of the
57 cases were found in Period B, and they composed $4.0 \%$ of the 1203 analyzed cases in that period and $6.1 \%$ of the 792 abnormal cases. The double trisomies involved all chromosomes except 1, 3, 11, 17, and 19.

\section{Processing time}

The interval of time from when a specimen arrived in our laboratory to when the results were reported was determined for both normal and abnormal results. The average turnaround time from a random sampling of $125 \mathrm{SABs}$ with normal karyotypes (10.9 days) compared to a random sampling of 130 trisomic cases (9.6 days) and the 80 multiple aneuploid 


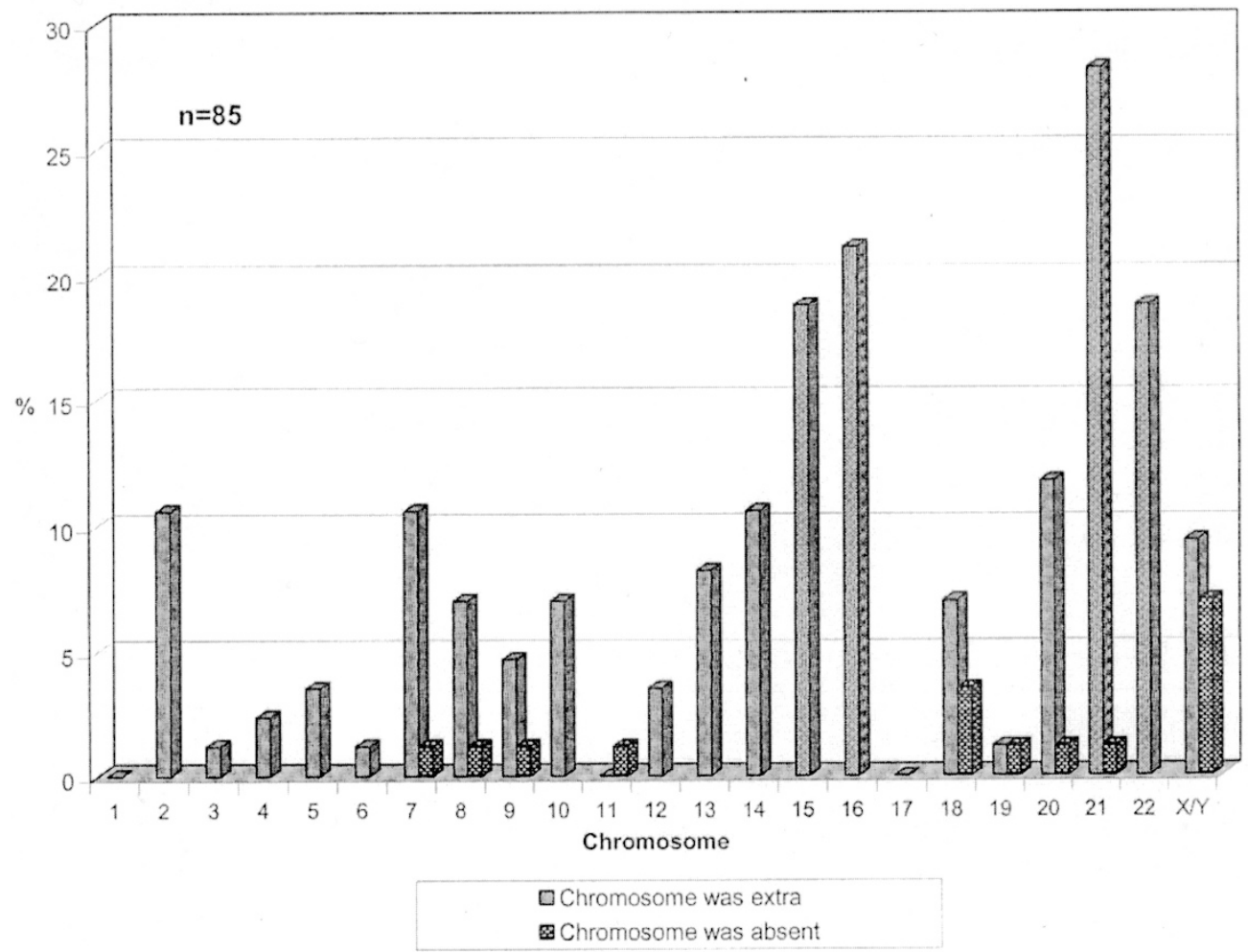

Fig. 2. Distribution of the extra or absent chromosomes in the multiple aneuploid cases.

cases (10.8 days) for which this data were available were not significantly different from each other.

\section{Maternal age}

Age data were available for only 241 (33.6\%) of the 717 analyzed specimens in Period A, with a mean maternal age of 35.6 (SD 5.8) years (Table 5). In Period B, ages were available for $98.4 \%$ of the 1203 cases, with a mean age of 36.6 (SD 5.2). The maternal ages were evenly distributed within each time period (data not shown).

Data from Period B was used to evaluate the correlation between maternal age and specific karyotype results. Maternal ages were available for 405 of the 411 specimens with normal karyotype, 518 of the 522 specimens with trisomy, and 71 of the 74 specimens with multiple aneuploidy. The mean ages of these three groups were found to be significantly different (Table 6), with the complexity of the karyotype abnormalities correlating with increasing maternal age.

\section{Comparison of results to previous studies}

Table 7 shows the data from Period A and compares it to previous studies that used similar harvesting techniques. The data from all of these studies includes over 10,000 specimens and the combined data are shown in the last column of the table. Due to variability in exclusion criteria or lack of information in the articles, it was difficult to calculate the actual percentage of growth failure and contamination in these early studies. Many of these articles reported high growth failure rates as well as the inability to karyotype POCs due to the absence of fetal tissue. ${ }^{3,4}$ The abnormality detection rate in almost all of these studies was $<50 \%$. The most notable exception was the early study by Boue et al. ${ }^{2}$ in which the majority of fetal specimens were collected immediately from women with a threatened abortion. Whereas the abnormality rate of Period A is comparable to the other POC harvesting studies, the distribution of the abnormalities differs. Of the studies shown in Table 7, Period A from the current study contained the oldest women.

Table 8 presents data from Period B and compares it to studies that used $\mathrm{CV}$ harvesting as well as comparative genomic hybridization (CGH) and interphase in situ hybridization (iFISH). The total data from all the CV harvesting studies includes over 2500 specimens and is shown in the table. With the exception of the study by Eiben et al., ${ }^{11}$ these studies are comparatively smaller than those found in Table 7. Culture and karyotype success rates were higher in this group than in the earlier collection of studies using POC harvesting. Abnormality rates were also higher in this group of studies, with all studies having an abnormality rate of $>50 \%$. The study by Eiben et al. ${ }^{11}$ had a low abnormality rate for this methodology when compared to the other studies and is responsible for reducing the total abnormality rate in this table. Unfortunately, the limited amount of maternal age data found in the articles referenced in both Table 7 and 8 makes analysis of this important factor difficult. 


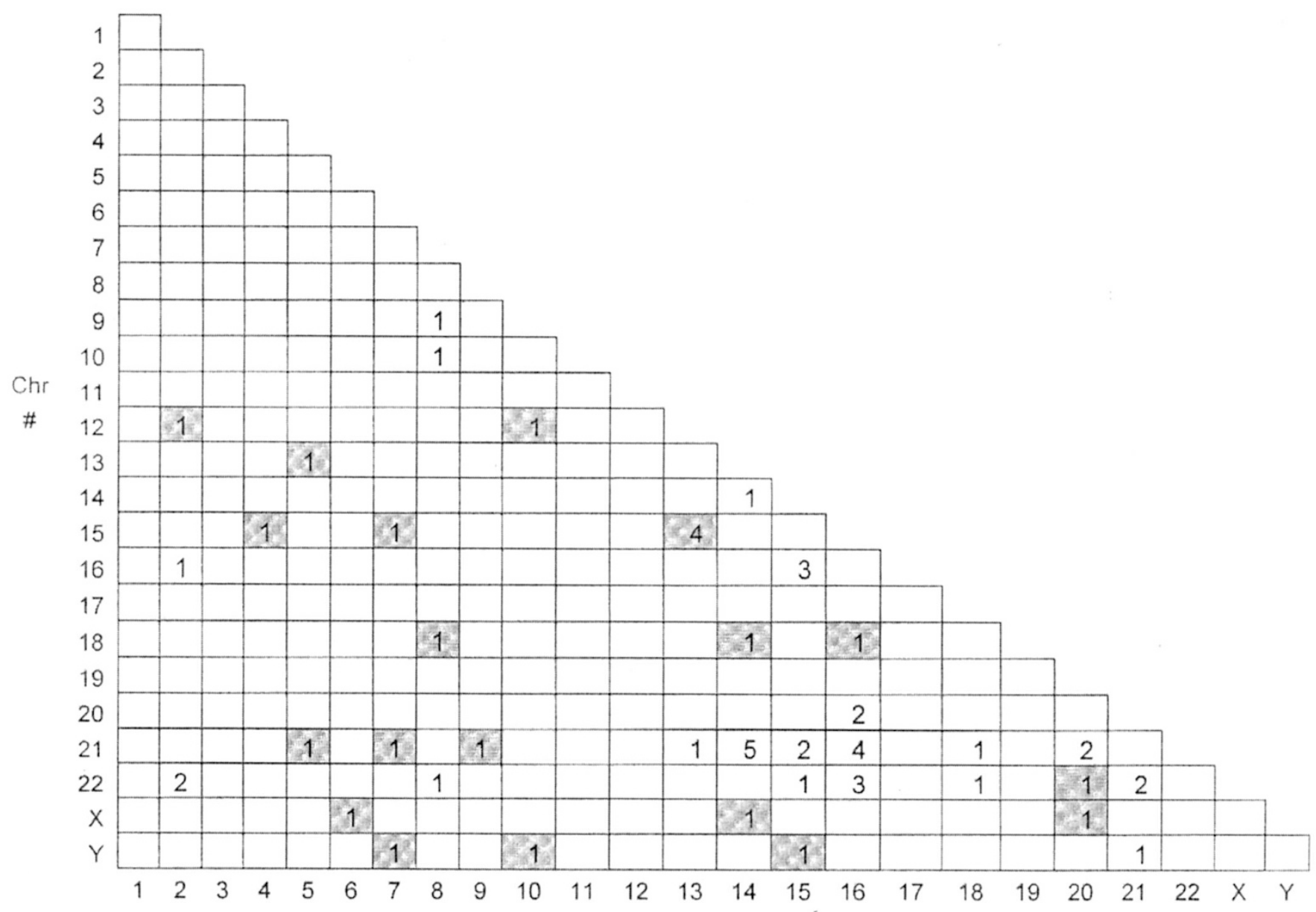

Chromosome number

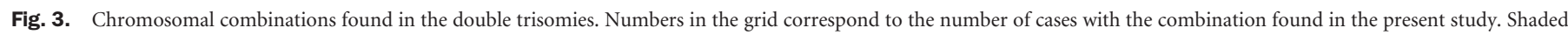
values indicate cases not previously reported in the literature. Figure adapted from: Reddy KS. Double trisomy in spontaneous abortions. Hum Genet 1997;101:339-345.22

\section{Probability table}

Using our data from Period B, a probability table was created according to maternal age to determine the likelihood that a POC would have a specific abnormality (Table 9). As maternal age increased, so did the odds of having an abnormal, aneuploid POC. Trisomies and multiple aneuploidies comprised over $70 \%$ of all SABs in women 40 years old or older.

\section{DISCUSSION}

This 12-year study provides additional insight into the distribution and types of chromosomal abnormalities that are found in SABs. With the modification of our technique, a significant improvement was found in diagnostic yield. This was largely due to a reduction in the percentage of specimens that were contaminated or that failed to grow. The $94.5 \%$ culture success rate in Period B allowed for more cases to be analyzed and is higher than the rate reported in most large case series..$^{3-5,9,11}$ Increased diagnostic yield was coupled with an increased detection of abnormal cases in Period B. Given the large overlap in the standard deviations and the clinical insignificance of a 1 -year difference between the mean ages (Table 5), the differences observed in the overall abnormality rates between the two periods can be attributed to the methodological changes implemented in our laboratory.

When comparing our data from Period A to previous studies using POC harvesting, maternal age was highest in our study. This increase in age is the most likely explanation for the higher rate of trisomies found in Period A. The overall rate of abnormalities (Table 7) is comparable due to the similar techniques used in acquiring tissue. The studies using CV harvesting have higher culture success and abnormality rates, but some of them also have a generally higher maternal age. ${ }^{12,13}$ This may be a reflection of women choosing to become pregnant later in life. This generalized increase in maternal age contributes to the higher abnormality rates detected using CV harvesting methodology. The link between nondisjunction and maternal age is also highly evident from the data presented in Table 6, which shows significantly higher mean ages among women with trisomies and multiple aneuploidies. 
Table 5

Age analysis of Women with SABs 1990-2002

\begin{tabular}{|c|c|c|c|c|c|c|c|}
\hline \multicolumn{4}{|c|}{ Period A } & \multicolumn{4}{|c|}{ Period B } \\
\hline Year & $\begin{array}{l}\text { Mean } \\
\text { age }\end{array}$ & SD & Cases $^{a}, \%$ & Year & $\begin{array}{c}\text { Mean } \\
\text { age }\end{array}$ & SD & Cases $^{a}, \%$ \\
\hline 1990 & 36.85 & 6.71 & $\begin{array}{c}46 \% \\
(\mathrm{n}=46)\end{array}$ & 1998 & 36.72 & 5.30 & $\begin{array}{c}97.95 \% \\
(\mathrm{n}=191)\end{array}$ \\
\hline 1991 & 35.15 & 5.96 & $\begin{array}{l}62.93 \% \\
(\mathrm{n}=73)\end{array}$ & 1999 & 36.22 & 5.53 & $\begin{array}{c}98.43 \% \\
(\mathrm{n}=250)\end{array}$ \\
\hline 1992 & 32.82 & 5.02 & $\begin{array}{c}25 \% \\
(\mathrm{n}=22)\end{array}$ & 2000 & 36.90 & 4.94 & $\begin{array}{c}97.76 \% \\
(\mathrm{n}=262)\end{array}$ \\
\hline 1996 & 34.88 & 3.64 & $\begin{array}{l}19.75 \% \\
(\mathrm{n}=16)\end{array}$ & 2001 & 37.05 & 5.29 & $\begin{array}{c}98.64 \% \\
(\mathrm{n}=218)\end{array}$ \\
\hline 1997 & 36.39 & 5.24 & $\begin{array}{l}77.78 \% \\
(\mathrm{n}=84)\end{array}$ & 2002 & 36.36 & 5.01 & $\begin{array}{c}99.25 \% \\
(\mathrm{n}=263)\end{array}$ \\
\hline Total & 35.55 & 5.75 & $\begin{array}{c}33.47 \% \\
(\mathrm{n}=241)\end{array}$ & Total & 36.63 & 5.21 & $\begin{array}{c}98.42 \% \\
(\mathrm{n}=1184)\end{array}$ \\
\hline
\end{tabular}

${ }^{a}$ Percent of analyzed cases for which age was available.

The abnormality rate of over $65 \%$ in Period B is higher than the $50 \%$ to $55 \%$ generally reported in large $\mathrm{SAB}$ studies using POC harvesting (Table 7). ${ }^{3-9}$ Comparable diagnostic yield $(>90 \%)$ and abnormality rates $(>60 \%)$ have been observed in smaller studies by investigators who performed CVS on patients at the time of fetal demise (Table 8). ${ }^{10,12-14}$ By selectively using chorionic villi or meticulously dissecting out fetal parts when villi are not available, the odds are greatly increased that fetal tissue is cultured.

The impact of age has to be considered when assembling data tables. Unfortunately, few age-related risk tables regarding POC results exist. ${ }^{6,10}$ For those cases where age data are available, direct comparison to our results is difficult due to the incompatible format of the available tables. Nevertheless, when an attempt is made to compare our abnormality distribution in Period B stratified by age (Table 9) to previous studies, similar trends and distributions are observed (comparison data not shown).6,10 The proportions of monosomic and polyploid karyotypes among abnormalities within each age group are quite similar, indicating that these proportions have not changed in almost 20 years. ${ }^{4}$ The data pooled from all the studies listed in Table 8 therefore gives one of the most comprehensive indications of the incidence and spectrum of chromosome abnormalities observed to date in POC specimens. Although the overall abnormality rate in POCs may in fact be closer to $70 \%$ (as indicated by the small CGH study ${ }^{24}$ ), the distribution of the abnormalities appears fairly constant with trisomies, triploidies, monosomy $\mathrm{X}$, multiple aneuploidies, structural abnormalities, tetraploidies, and autosomal monosomies (essentially monosomy 21 ), accounting for approximately $64 \%, 11 \%, 10 \%, 6 \%, 4 \%, 4 \%$, and $1 \%$ of all abnormalities, respectively.
Table 6

Correlation of karyotype result and maternal age

\begin{tabular}{lccrr}
\hline Karyotype & Mean age & SD & $P$ value & $P$ value $^{b}$ \\
\hline Normal & 35.10 & 5.44 & & \\
Abnormal & 37.43 & 4.90 & $<0.05$ & \\
Polyploid & 34.31 & 5.51 & 0.20 & \\
Monosomy & 35.25 & 5.01 & 0.83 & \\
Trisomy & 38.13 & 4.23 & $<0.05$ & \\
Multiple aneuploidy & 40.29 & 4.07 & $<0.05$ & $<0.05$ \\
\hline
\end{tabular}

${ }^{a}$ Mean age in relation to maternal age of normal karyotypes; ${ }^{b}$ Mean age in relation to maternal age of trisomic karyotypes.

Monosomies were the only abnormality group where the difference between the two periods lost significance when logistic regression was applied. Because all cases in Period A and about $81 \%$ of cases in Period B were monosomy X, this finding is not surprising as the risk of monosomy $\mathrm{X}$ is not influenced by maternal age. ${ }^{26}$ As such, the detection rate of this abnormality appears to have remained unchanged over time, irrespective of methodology (POC harvesting versus CV harvesting). This constant rate supports the possibility that cases of monosomy $\mathrm{X}$ spontaneously abort later in gestation. Because there is more fetal tissue at a later time of abortion, POC harvesting techniques would be more likely to succeed in detecting cases of monosomy $\mathrm{X}$ in cultured specimens. CV harvesting would then be expected to have similar detection rates.

Investigators using POC harvesting frequently mention that monosomy X accounts for approximately $15 \%$ to $20 \%$ of abnormal SABs. ${ }^{2-5,7-9,27}$ With CV harvesting, the detection rate of monosomies has remained constant while the detection rate of other abnormalities has increased. As such, the concomitant prevalence of monosomies among all abnormalities has decreased. Based on our review of more recent studies (including the present study), the incidence of monosomy $\mathrm{X}$ appears comparable to the triploidy rate with each around 10\% (Table 8).

Our study revealed that the presence or the complexity of an abnormality was not associated with the length of time required to obtain a result. While certain abnormalities may fail to establish themselves in culture, the type of abnormality does not appear to influence the growth rate once the culture is successfully initiated. Certain abnormalities may in fact have decreased viability in culture and the differences observed using POC versus CV harvesting indicates that the type of technique and the gestational age of the specimen play a role in culture success/failure. Molecular cytogenetic studies will certainly provide valuable information regarding the correlation between specific abnormalities and their ability to be cultured.

Our collection of double trisomies and multiple aneuploidies reflects the variety of abnormalities that can and do occur during the various stages of meiosis and postzygotic division. Multiple aneuploid karyotypes were observed in ad- 
vancing age, implying a direct correlation between maternal age and the complexity of the chromosomal abnormalities observed. ${ }^{22}$ This series of 85 multiple aneuploidies is the largest described to date and includes unique combinations that have not been reported previously.22,28 The high number of these cases is probably attributable to the advanced age of our patient population, the use of CV harvesting, and the prompt initiation of culture upon receipt of the specimen.

The chromosomes most frequently involved in our multiple aneuploidies were $7,14,15,16,21$, and 22 . The 57 double trisomies reported involved all chromosomes except 1, 3, 11, 17, and 19. The absence of 1 and 19 in this group is not surprising as they parallel their low frequency in our trisomy group as well. The absence of 3,11, and 17 may be either reflective of our sample size or representative of the delicate interaction of various developmental genes that reside on these chromosomes. The origin and mechanism of producing human aneuploidy is difficult to investigate as this phenomenon is not frequently observed in lower animals. ${ }^{29}$ Recent literature suggests a predisposition to nondisjunction associated with reduced recombination and that aberrant recombination appears to increase with advanced maternal age. 18,29,30
Consistent with other studies, trisomies 16, 22, and 21 continue to be the most common abnormalities in SABs. ${ }^{3,4,11,20}$ Those chromosomes found infrequently (i.e., chromosomes 1 and 19) are those that lead to earlier, undetected SABs or fail to establish a viable pregnancy. Trisomy 1 has only been reported twice in the literature ${ }^{31,32}$ and trisomy 19 has been reported once using molecular cytogenetic techniques. ${ }^{24}$ Chromosome 19 is known to be particularly gene-rich and probably has many critical genes that require precise dosage for normal development. Trisomy 16 is usually the most common trisomy, as was found in Period B. Trisomy 21 was the most common trisomy in Period A. This may have been an accurate reflection of our findings, but is more likely due to the failure to detect additional cases of trisomy 16 , either due to maternal/bacterial contamination or culture failure.

As important as it is to assess the abnormal findings in our study, it is equally important to evaluate any trends found in the normal karyotypes. When determining the sex ratio of normal karyotypes, the techniques used for setting up POC samples are particularly relevant. When a normal cytogenetic result is obtained, the validity of the 46,XX karyotype must be considered, as maternal cell contamination cannot be ruled

Table 7

Comparison of studies using POC harvesting to results of Period A

\begin{tabular}{|c|c|c|c|c|c|c|c|c|c|c|}
\hline & $\begin{array}{c}\text { Boue }^{2} \\
1975\end{array}$ & $\begin{array}{c}\mathrm{Kajii}^{3} \\
1980\end{array}$ & $\begin{array}{c}\text { Hassold }^{4} \\
1980\end{array}$ & $\begin{array}{c}\text { Warburton }^{5} \\
1980\end{array}$ & $\begin{array}{c}\text { Hassold }^{6} \\
1985\end{array}$ & $\begin{array}{l}\operatorname{Lin}^{7} \\
1985\end{array}$ & $\begin{array}{c}\text { Kline }^{8} \\
1987\end{array}$ & $\begin{array}{c}\text { Dejmek }^{9} \\
1992\end{array}$ & $\begin{array}{c}\text { Current } \\
\text { Period A }\end{array}$ & Total \\
\hline \multicolumn{11}{|l|}{ Maternal age } \\
\hline Average & NA & $29.5 \pm 6.3$ & $27.5 \pm 6.3$ & NA & NA & 26 & NA & $26.6 \pm 6.0$ & $35.7 \pm 5.8$ & \\
\hline Normal & $27.5 \pm 0.4$ & $28.9 \pm 6.0$ & $27.0 \pm 6.0$ & $\mathrm{NA}$ & $27.1 \pm 5.9$ & 26 & 27 & $26.4 \pm 5.9$ & $34.8 \pm 6.0$ & \\
\hline Abnormal & NA & $30.1 \pm 6.6$ & NA & NA & NA & 26.1 & NA & $26.7 \pm 6.2$ & $36.4 \pm 5.1$ & \\
\hline Trisomy & $31.3 \pm 0.6$ & $31.9 \pm 6.5$ & $29.8 \pm 6.1$ & $\mathrm{NA}$ & $30.3 \pm 6.1$ & 27.7 & $\mathrm{NA}$ & $27.7 \pm 6.7$ & $37.8 \pm 4.0$ & \\
\hline Double & $35.0 \pm 6.1$ & $37.9 \pm 4.8$ & $33.2 \pm 6.4$ & NA & NA & 27.5 & 36.5 & $29.7 \pm 6.0$ & $30.1^{b}$ & \\
\hline Total set up & $\mathrm{NA}$ & $639^{a}$ & $1120^{a}$ & 1636 & NA & 428 & NA & 1508 & 907 & \\
\hline Total analyzed & 1498 & 447 & 1000 & 967 & 2264 & 215 & 2098 & 926 & 717 & 10132 \\
\hline Total normal (\%) & 38.5 & 46.1 & 53.7 & 67.7 & 49.6 & 62.8 & 62.4 & 54.0 & 57.2 & 53 \\
\hline Male (\%) & NA & 53.9 & 42.8 & 47.0 & NA & 31.9 & $\mathrm{NA}$ & 57.2 & 24.6 & 46 \\
\hline Female (\%) & NA & 46.1 & 57.2 & 53.0 & NA & 68.1 & NA & 42.8 & 75.4 & 54 \\
\hline M:F Ratio & NA & 1.17 & 0.75 & 0.89 & NA & 0.47 & NA & 1.34 & 0.33 & 0.85 \\
\hline Total abnormal (\%) & 61.5 & 53.9 & 46.3 & 32.3 & 50.4 & 37.2 & 37.6 & 46.0 & 42.8 & 47 \\
\hline Trisomy (\%) & 52.0 & 57.3 & 44.5 & 53.2 & 56.2 & 33.8 & 47.4 & 47.4 & 64.8 & 52 \\
\hline Mono X (\%) & 15.2 & 18.3 & 24.2 & 15.4 & 18.7 & 20.0 & 16.3 & 18.3 & 13.7 & 17 \\
\hline Triploid (\%) & 19.9 & 11.2 & 14.5 & 15.7 & NA & 3.8 & 14.6 & 17.8 & 10.4 & 16 \\
\hline Tetraploid (\%) & 6.2 & 2.5 & 6.9 & 4.5 & NA & 3.8 & 5.2 & 8.0 & 1.6 & 6 \\
\hline Multiple (\%) & NA & 5.0 & 3.5 & NA & NA & 3.8 & 1.9 & 2.8 & 3.6 & 3 \\
\hline Double (\%) & 1.7 & 2.9 & 2.6 & 1.3 & NA & 3.8 & NA & 2.3 & 2.9 & 2 \\
\hline Structural (\%) & 3.8 & 4.6 & 4.3 & 2.9 & 2.4 & 7.5 & NA & 4.5 & 4.9 & 4 \\
\hline
\end{tabular}

Data adjusted to reflect definitions of terms used in this current study. Mono X, Cases of Monosomy X; Multiple, Cases of Multiple Aneuploidy; Double, Cases of Double Aneuploidy; Total, Derived from studies using POC harvesting where data was available (includes current study).

${ }^{a}$ Additional cases were submitted but not deemed eligible and included cases which failed to grow in culture; ${ }^{b}$ Only one case available for reporting. 
Table 8

Comparison of studies using CV Harvesting or CGH/iFISH to results of Period B

\begin{tabular}{|c|c|c|c|c|c|c|c|c|c|}
\hline & \multicolumn{7}{|c|}{ CV Harvesting } & \multirow{2}{*}{$\begin{array}{c}\text { CGH } \\
\text { Fritz }^{24} \\
2001 \\
\end{array}$} & \multirow{2}{*}{$\begin{array}{c}\text { iFISH } \\
\text { Lebedev }^{25} \\
2004 \\
\end{array}$} \\
\hline & $\begin{array}{c}\text { Guerneri }^{10} \\
1987\end{array}$ & $\begin{array}{c}\text { Eiben }^{11} \\
1990\end{array}$ & $\begin{array}{c}\text { Strom }^{12} \\
1992\end{array}$ & $\begin{array}{c}\text { Sanchez }^{13} \\
1999\end{array}$ & $\begin{array}{l}\text { Philipp }^{14} \\
2003\end{array}$ & $\begin{array}{l}\text { Current } \\
\text { Period B }\end{array}$ & Total $^{a}$ & & \\
\hline \multicolumn{10}{|l|}{ Maternal age } \\
\hline Average & NA & NA & 37.7 & 31.7 & NA & $36.5 \pm 5.2$ & & NA & NA \\
\hline Normal & NA & $28.8 \pm 6.1$ & 36 & NA & NA & $35.1 \pm 5.4$ & & $29.9 \pm 3.9$ & $26.3 \pm 5.8$ \\
\hline Abnormal & NA & $31.6 \pm 5.9$ & NA & NA & NA & $37.4 \pm 4.9$ & & $32.4 \pm 5.0$ & NA \\
\hline Trisomy & NA & $33.5 \pm 6.3$ & 38.4 & NA & NA & $38.1 \pm 4.2$ & & $32.0 \pm 5.0$ & NA \\
\hline Double & NA & $35.1 \pm 9.6$ & NA & NA & NA & $40.9 \pm 4.0$ & & NA & NA \\
\hline Total set up & 202 & 983 & 96 & 93 & 233 & 1273 & 2880 & 60 & 60 \\
\hline Total analyzed & 189 & 750 & 95 & 85 & 221 & 1203 & 2543 & 57 & 60 \\
\hline Total normal (\%) & 23.3 & 49.3 & 16.8 & 37.6 & 25.3 & 34.2 & 37 & 28.1 & 46.7 \\
\hline Male (\%) & 36.4 & 41.6 & 56.3 & NA & NA & 41.6 & 42 & 43.8 & NA \\
\hline Female (\%) & 63.6 & 58.4 & 43.8 & NA & NA & 58.4 & 58 & 56.3 & NA \\
\hline M:F Ratio & 0.56 & 0.71 & 1.29 & NA & NA & 0.71 & 0.71 & 0.78 & NA \\
\hline Total abnormal (\%) & 76.7 & 50.7 & 83.2 & 62.4 & 74.7 & 65.8 & 63 & 71.9 & 53.3 \\
\hline Trisomy (\%) & 61.4 & 60.3 & $75.9^{b}$ & $62.3^{b}$ & $61.2^{b}$ & 65.9 & 64 & 68.3 & 50.0 \\
\hline Mono X (\%) & 8.3 & 10.5 & 11.4 & 7.5 & 22.4 & 6.8 & 10 & 9.8 & 12.5 \\
\hline Triploid (\%) & 7.6 & 12.4 & 6.3 & 26.4 & 9.7 & 10.6 & 10 & $17.1^{c}$ & 9.4 \\
\hline Tetraploid (\%) & 2.1 & 9.2 & 3.8 & 1.9 & 1.8 & 1.6 & 2 & 0 & 6.3 \\
\hline Multiple (\%) & 9.7 & 2.4 & 1.3 & 0 & 0 & 7.3 & 6 & 0 & 3.1 \\
\hline Structural (\%) & 8.3 & 4.7 & 1.3 & 1.9 & 4.8 & 3.9 & 4 & 2.4 & 0 \\
\hline
\end{tabular}

Data adjusted to reflect definitions of terms used in this current study. iFISH, interphase fluorescence in situ hybridization; CGH, comparative genomic hybridization; Mono X, Cases of Monosomy X; Multiple, Cases of Multiple Aneuploidy; Double, Cases of Double Aneuploidy.

${ }^{a}$ Derived from studies using CV harvesting where data was available.

${ }^{b}$ Studies in which trisomy 16 was not the most common trisomy.

${ }^{c}$ Ploidy determined using microsatellite and FISH analysis.

Table 9

Probability of a particular karyotype in a POC based on maternal age

\begin{tabular}{|c|c|c|c|c|c|c|c|c|}
\hline Age & Normal & Abnormal & $\begin{array}{c}\text { Trisomy } \\
\text { (Likelihood of } \\
\text { trisomy 16) }\end{array}$ & $\begin{array}{c}\text { Monosomy } \\
\text { (Likelihood of } \\
\text { monosomy X) }\end{array}$ & Triploidy & Tetraploidy & $\begin{array}{c}\text { Multiple } \\
\text { aneuploidy }\end{array}$ & Other \\
\hline \multirow[t]{2}{*}{$<25$} & 64.3 & 35.7 & 3.6 & 3.6 & 17.9 & 0.0 & 0.0 & 10.7 \\
\hline & & & $(0.0)$ & (3.6) & & & & \\
\hline \multirow[t]{2}{*}{$25-29$} & 50.5 & 49.5 & 17.5 & 9.3 & 13.4 & 1.0 & 2.1 & 6.2 \\
\hline & & & $(1.0)$ & $(8.2)$ & & & & \\
\hline \multirow[t]{2}{*}{$30-34$} & 43.0 & 57.0 & 34.0 & 7.2 & 10.0 & 1.4 & 1.4 & 3.0 \\
\hline & & & $(10.4)$ & (6.8) & & & & \\
\hline \multirow[t]{2}{*}{$35-39$} & 32.2 & 67.8 & 47.5 & 5.6 & 6.5 & 0.9 & 5.2 & 2.1 \\
\hline & & & $(8.1)$ & (4.3) & & & & \\
\hline \multirow[t]{2}{*}{$40+$} & 22.3 & 77.7 & 57.7 & 3.0 & 2.1 & 1.2 & 12.5 & 1.3 \\
\hline & & & (8.6) & (1.8) & & & & \\
\hline
\end{tabular}

${ }^{a}$ Data is presented as a percentage (\%) and is derived from all cases analyzed in Period B for which age was available. 
out without additional molecular testing. Period A's male-tofemale ratio of 0.33 was very low and is likely reflective of a high level of maternal contamination, whereas Period B revealed a male-to-female sex ratio of 0.71 . This ratio is identical to the total ratio calculated from all the studies listed in Table $8^{3,11,12,24,33,34}$ and is also similar to that obtained by Fritz et al..$^{24}$ using CGH. The literature remains unclear as to the expected ratio of males to females in early gestation through the second trimester, and the ratio varies considerably in the various studies. ${ }^{3-5,7,9-12,24,33,35}$ The lower the sex ratio of males to females, the greater the likelihood of maternal cell contamination. As such, the POCs of Period B appear to more accurately reflect fetal karyotypes. A sex ratio of 0.71 , however, may still reflect an element of maternal contamination and, as indicated by the CGH study, ${ }^{24}$ it remains possible that additional abnormal cases could have been detected.

With the improvements in obstetrical care, pregnancies are detected earlier and SABs are evaluated more frequently. Early losses, which are more likely to have abnormal karyotypes, are submitted for cytogenetic studies. This may contribute to the higher abnormality rate detected in Period B. Because gestational age at the time of abortion is not provided to our laboratory, the impact of this important factor could not be addressed in this study. Time bias may have influenced our findings, as random chance could have caused the various dis- tributions in our results. The influence of this bias is minimized by the large, consistent, and statistically significant differences found between our two periods. Finally, the origins of the mosaic cases are open to various interpretations. Because infertility specialists requested many of the analyses, it is possible that the losses were from multiple gestations. There is also the possibility of in vitro loss of chromosomes in those cases that were in culture for a long period of time.

\section{CONCLUSION}

Through our study, we have shown that improvements in laboratory technique have led to reduced contamination and growth failure of POCs, irrespective of maternal age. Furthermore, these improvements have led to a more balanced male to female ratio and to the detection of an increased number of abnormal cases. Maternal age continues to play an important and consistent role in determining abnormality distribution. Advanced maternal age is associated with an increased likelihood of aneuploidy and multiple aneuploidy. The 85 cases of multiple aneuploidy reported display a wide range of karyotypic abnormalities and help to further advance our knowledge of the abnormalities associated with SABs. Newer methodologies using CGH and iFISH will be useful in detecting additional abnormalities. 


\begin{tabular}{|c|c|c|c|}
\hline Year & Double Trisomy & Year & Pseudodiploid \\
\hline 1990 & $48, \mathrm{XY},+16,+21$ & 1996 & $46, X,+22$ \\
\hline 1991 & $48, \mathrm{XY},+14,+21$ & 1998 & $46, X,+10$ \\
\hline 1991 & $48, \mathrm{XY},+8,+9$ & 1998 & $46, X,+16$ \\
\hline 1992 & $48, \mathrm{XYY},+10$ & 1999 & $46, \mathrm{X},+22$ \\
\hline 1994 & $48, \mathrm{XY},+20,+22$ & 1999 & $46, \mathrm{XY},+20,-21$ \\
\hline 1996 & $48, \mathrm{XXX},+20$ & 2000 & $46, X,+16$ \\
\hline 1996 & $48, \mathrm{XXY},+7$ & 2001 & $46, X,+15$ \\
\hline 1997 & $48, \mathrm{XX},+13,+21$ & & \\
\hline 1998 & $48, \mathrm{XX},+15,+21$ & & Polysomy \\
\hline 1998 & $48, \mathrm{XX},+16,+20$ & 1998 & $49, \mathrm{XX},+2,+9,+15$ \\
\hline 1998 & $48, \mathrm{XX},+21,+22$ & 1998 & $51, \mathrm{XX},+2,+8,+20,+21,+22$ \\
\hline 1998 & $48, \mathrm{XX},+7,+21$ & 1999 & $49, \mathrm{XX},+18,+20,+21$ \\
\hline 1998 & $48, \mathrm{XX},+8,+10$ & 2000 & $49, \mathrm{XX},+8,+21,+22$ \\
\hline 1998 & $48, \mathrm{XXY},+15$ & 2001 & $49, \mathrm{XY},+7,+10,+12$ \\
\hline 1998 & $48, \mathrm{XY},+13,+15$ & 2002 & $50, \mathrm{XYY},+2,+7,+13$ \\
\hline 1998 & $48, \mathrm{XY},+7,+15$ & & \\
\hline 1998 & $48, X Y Y, \operatorname{inv}(9)(p 11 q 13),+21$ & & Near/Pseudo Triploid \\
\hline 1999 & $48, \mathrm{XX},+15,+16$ & 1998 & $75, \mathrm{XXX},+4,+5,+7,+14,+19,+20$ \\
\hline 1999 & $48, \mathrm{XX},+15,+21$ & 1999 & $69, \mathrm{XXX},+7,-18$ \\
\hline 1999 & $48, \mathrm{XX},+15,+22$ & 1999 & $70, \mathrm{XXX},+3$ \\
\hline 1999 & $48, \mathrm{XX},+2,+16$ & 1999 & $70, \mathrm{XXY},+2,+10,-18$ \\
\hline 1999 & $48, \mathrm{XX},+4,+15$ & 2000 & $68, \mathrm{XXY},-7$ \\
\hline 1999 & $48, \mathrm{XXX},+14$ & 2001 & $70, \mathrm{XXY},+16$ \\
\hline 1999 & $48, \mathrm{XY},+16,+21$ & 2002 & $69, \mathrm{XXY},+9,-18$ \\
\hline 1999 & $48, \mathrm{XY},+16,+22$ & & \\
\hline 1999 & $48, \mathrm{XY},+16,+22$ & & Near Tetraploid \\
\hline 1999 & $48, \mathrm{XY},+18,+21$ & 1997 & $90, X X Y Y,-9,-19$ \\
\hline 1999 & $48, \mathrm{XY},+9,+21$ & 1999 & $90, \mathrm{XX}$ \\
\hline 2000 & $48, \mathrm{XX},+13,+15$ & 2000 & $96, \mathrm{XXXX},+7,+7,+15,+15$ \\
\hline 2000 & $48, \mathrm{XX},+15,+16$ & 2002 & $91, \mathrm{XXXX},-20$ \\
\hline 2000 & $48, \mathrm{XX},+2,+22$ & 2002 & $93, \mathrm{XXYY},-11,+7,+7$ \\
\hline 2000 & $48, \mathrm{XX},+20,+21$ & 2002 & $94, \mathrm{XXXX},+22,+22$ \\
\hline 2000 & $48, \mathrm{XX},+8,+22$ & & \\
\hline 2000 & $48, \mathrm{XXX},+6$ & & Mosaic \\
\hline 2000 & $48, \mathrm{XY},+14,+18$ & 1995 & $47, \mathrm{XY},+3 / 48, \mathrm{XY},+8,+18$ \\
\hline 2000 & $48, \mathrm{XY},+14,+21$ & 2002 & $47, \mathrm{XY},+16 / 94, \mathrm{XXYY},+16,+16$ \\
\hline 2000 & $48, \mathrm{XY},+14,+21$ & 2002 & $91, \mathrm{XXXX},-8 / 91, \mathrm{XXXX},+2,-8,-8 / 92, \mathrm{XXXX}$ \\
\hline 2000 & $48, \mathrm{XY},+14,+21$ & & \\
\hline 2000 & $48, \mathrm{XY},+15,+16$ & & Complex \\
\hline 2000 & $48, \mathrm{XY},+16,+21$ & 1999 & $47, \mathrm{XX}, \operatorname{der}(14 ; 14)(\mathrm{q} 10 ; \mathrm{q} 10),+14,+14$ \\
\hline 2000 & $48, \mathrm{XY},+16,+22$ & 2002 & $47, \mathrm{XX}, \operatorname{der}(13 ; 14)(\mathrm{q} 10 ; \mathrm{q} 10),+13,+15$ \\
\hline 2000 & $48, \mathrm{XY},+2,+12$ & & \\
\hline 2000 & $48, \mathrm{XY},+20,+21$ & & \\
\hline 2000 & $48, \mathrm{XY},+5,+13$ & & \\
\hline 2001 & $48, \mathrm{XY},+10,+12$ & & \\
\hline 2001 & $48, \mathrm{XY},+13,+15$ & & \\
\hline 2001 & $48, \mathrm{XY},+16,+18$ & & \\
\hline 2001 & $48, X Y,+16,+20$ & & \\
\hline 2001 & $48, \mathrm{XY},+18,+22$ & & \\
\hline 2001 & $48, \mathrm{XY},+2,+22$ & & \\
\hline 2002 & $48, \mathrm{XX},+14,+21$ & & \\
\hline 2002 & $48, \mathrm{XX},+16,+21$ & & \\
\hline 2002 & $48, \mathrm{XX},+5, \operatorname{inv}(9)(\mathrm{p} 11 \mathrm{q} 13),+21$ & & \\
\hline 2002 & $48, \mathrm{XY},+21,+22$ & & \\
\hline
\end{tabular}




\section{References}

1. Bowen P, Lee CS. Spontaneous abortion. Chromosome studies on 41 cases and an analysis of maternal age and duration of pregnancy in relation to karyotype. Am J Obstet Gynecol 1969;104:973-983.

2. Boue J, Bou A, Lazar P. Retrospective and prospective epidemiological studies of 1500 karyotyped spontaneous human abortions. Teratology 1975;12:11-26.

3. Kajii T, Ferrier A, Niikawa N, Takahara H, Ohama K, Avirachan S. Anatomic and chromosomal anomalies in 639 spontaneous abortuses. Hum Genet 1980;55:87-98.

4. Hassold T, Chen N, Funkhouser J, Jooss T, Manuel B, Matsuura J et al. A cytogenetic study of 1000 spontaneous abortions. Ann Hum Genet 1980;44:151-178.

5. Warburton D, Stein Z, Kline J, Susser M. Chromosome abnormalities in spontaneous abortion: Data from the New York City study. In: Porter IH, Hook EB, editors. Embryonic and fetal death. New York: Academic Press 1980;261-287.

6. Hassold T, Chiu D. Maternal age-specific rates of numerical chromosome abnormalities with special reference to trisomy. Hum Genet 1985;70:11-17.

7. Lin CC, De Braekeleer M, Jamro H. Cytogenetic studies in spontaneous abortion: the Calgary experience. Can J Genet Cytol 1985;27:565-570.

8. Kline J, Stein Z. Epidemiology of Chromosomal Anomalies in Spontaneous Abortion: Prevalence, Manifestation and Determinants. In: Bennett MJ, Edmonds DK, editors. Spontaneous and Recurrent Abortion. Chicago: Oxford Blackwell Scientific 1987;29-50.

9. Dejmek J, Vojtassak J, Malova J. Cytogenetic analysis of 1508 spontaneous abortions originating from south Slovakia. Eur J Obstet Gynecol Reprod Biol 1992;46:129-136.

10. Guerneri S, Bettio D, Simoni G, Brambati B, Lanzani A, Fraccaro M. Prevalence and distribution of chromosome abnormalities in a sample of first trimester internal abortions. Hum Reprod 1987;2:735-739.

11. Eiben B, Bartels I, Bahr-Porsch S, Borgmann S, Gatz G, Gellert G et al. Cytogenetic analysis of 750 spontaneous abortions with the direct- preparation method of chorionic villi and its implications for studying genetic causes of pregnancy wastage. Am J Hum Genet 1990;47:656-663.

12. Strom CM, Ginsberg N, Applebaum M, Bozorgi N, White M, Caffarelli M et al. Analyses of 95 first-trimester spontaneous abortions by chorionic villus sampling and karyotype. J Assist Reprod Genet 1992;9:458-461.

13. Sanchez JM, Franzi L, Collia F, De Diaz SL, Panal M, Dubner M. Cytogenetic study of spontaneous abortions by transabdominal villus sampling and direct analysis of villi. Prenat Diagn 1999;19:601-603.

14. Philipp T, Philipp K, Reiner A, Beer F, Kalousek DK. Embryoscopic and cytogenetic analysis of 233 missed abortions: factors involved in the pathogenesis of developmental defects of early failed pregnancies. Hum Reprod 2003;18:1724-1732.

15. Wilcox AJ, Weinberg CR, Wehmann RE, Armstrong EG, Canfield RE, Nisula BC. Measuring early pregnancy loss: laboratory and field methods. Fertil Steril 1985;44: $366-374$.
16. Wilcox AJ, Weinberg CR, O`Connor JF, Baird DD, Schlatterer JP, Canfield RE, Armstrong EG, Nisula BC. Incidence of early loss of pregnancy. N Engl J Med 1988; 319:189-194.

17. McFadden DE, Friedman JM. Chromosome abnormalities in human beings. Mutat Res 1997;396:129-140.

18. Robinson WP, McFadden DE, Stephenson MD. The origin of abnormalities in recurrent aneuploidy/polyploidy. Am J Hum Genet 2001;69:1245-1254.

19. Cohen J. Sorting out chromosome errors. Science 2002;296:2164-2166.

20. Hassold T, Abruzzo M, Adkins K, Griffin D, Merrill M, Millie E et al. Human aneuploidy: incidence, origin, and etiology. Environ Mol Mutagen 1996;28:167-175.

21. Pergament E, Kadotani T, Sato H. Double trisomy in the spontaneous abortion population. Am J Obstet Gynecol 1969;104:984-987.

22. Reddy KS. Double trisomy in spontaneous abortions. Hum Genet 1997;101:339-345.

23. Li S, Hassed S, Mulvihill JJ, Nair AK, Hopcus DJ. Double trisomy. Am J Med Genet 2004;124A:96-98.

24. Fritz B, Hallermann C, Olert J, Fuchs B, Bruns M, Aslan M et al. Cytogenetic analyses of culture failures by comparative genomic hybridisation (CGH)-Re-evaluation of chromosome aberration rates in early spontaneous abortions. Eur J Hum Genet 2001;9:539-547.

25. Lebedev IN, Ostroverkhova NV, Nikitina TV, Sukhanova NN, Nazarenko SA. Features of chromosomal abnormalities in spontaneous abortion cell culture failures detected by interphase FISH analysis. Eur J Hum Genet 2004;1-8.

26. Hassold T, Arnovitz K, Jacobs PA, May K, Robinson D. The parental origin of the missing or additional chromosome in 45,X and 47,XXX females. Birth Defects Orig Artic Ser 1990;26:297-304.

27. Gardner RJM, Sutherland GR. Chromosome Abnormalities and Genetic Counseling. Oxford, UK: Oxford University Press; 2004:577.

28. Reddy KS. Triple aneuploidy in spontaneous abortions. Clin Genet 1999;56:103104.

29. Hassold T, Hunt P. To err (meiotically) is human: the genesis of human aneuploidy. Nat Rev Genet 2001;2:280-291.

30. Wells D, Levy B. Cytogenetics in reproductive medicine: the contribution of com parative genomic hybridization (CGH). Bioessays 2003;25:289-300.

31. Dunn TM, Grunfeld L, Kardon NB. Trisomy 1 in a clinically recognized IVF pregnancy. Am J Med Genet 2001;99:152-153.

32. Hanna JS, Shires P, Matile G. Trisomy 1 in a clinically recognized pregnancy. Am J Med Genet 1997;68:98.

33. Bartels I, Hansmann I, Eiben B. Excess of females in chromosomally normal spontaneous abortuses. Am J Med Genet 1990;35:297-298.

34. Smith MJ, Creasy MR, Clarke A, Upadhyaya M. Sex ratio and absence of uniparental disomy in spontaneous abortions with a normal karyotype. Clin Genet 1998;53:258 261.

35. Hassold T, Quillen SD, Yamane JA. Sex ratio in spontaneous abortions. Ann Hum Genet 1983;47:39-47. 